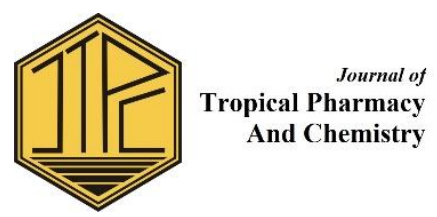

\title{
WITHDRAWAL: Molluscicidal activities of Tetrapleura tetraptera fruit extract, Aridanin and their particulate formulations on adult and newly hatched Biomphalaria glabrata snails
}

\section{Ganiyu Akinniyi, Funmilola Fisusi, Bamigboye Taiwo}

Withdrawal Notice: This article is withdrawn at the authors' request.

\section{REFERENCES}

Akinniyi, G., Fisusi, F., \& Taiwo, B. (2019). Molluscicidal activities of Tetrapleura tetraptera fruit extract, Aridanin and their particulate formulations on adult and newly hatched Biomphalaria glabrata snails. Journal of Tropical Pharmacy and Chemistry, 4(6), 281-297. https://doi.org/10.25026/jtpc.v4i6.217 